\title{
Pulmonary hypertensive vasculopathy in parenchymal lung diseases and/or hypoxia
}

\author{
Maria Rosa Ghigna ${ }^{1}$, Wolter J. Mooi ${ }^{2}$ and Katrien Grünberg ${ }^{3}$ \\ Number 1 in the Series "Pathology for the clinician" \\ Edited by Peter Dorfmüller and Alberto Cavazza
}

Affiliations: 'Service d'Anatomie et de Cytologie Pathologiques, Hôpital Marie Lannelongue, Le Plessis Robinson, France. ${ }^{2}$ Dept of Pathology, VU University Medical Center, Amsterdam, The Netherlands. ${ }^{3}$ Dept of Pathology, Radboud UMC, Nijmegen, The Netherlands.

Correspondence: Maria Rosa Ghigna, Service d'Anatomie et de Cytologie Pathologiques, Hôpital Marie Lannelongue, 133 avenue de la Résistance, Le Plessis Robinson 92350, France. E-mail: mr.ghignaAccml.fr

@ERSpublications

Parenchymal lung diseases and/or hypoxia exposure are risk factors for pulmonary hypertension http://ow.ly/vMpP30belX1

Cite this article as: Ghigna MR, Mooi WJ, Grünberg K. Pulmonary hypertensive vasculopathy in parenchymal lung diseases and/or hypoxia. Eur Respir Rev 2017; 26: 170003 [https://doi.org/10.1183/ 16000617.0003-2017].

ABSTRACT Pulmonary hypertension $(\mathrm{PH})$ with complicating chronic lung diseases and/or hypoxia falls into group 3 of the updated classification of $\mathrm{PH}$. Patients with chronic obstructive lung disease (COPD), diffuse lung disease (such as idiopathic pulmonary fibrosis (IPF)) and with sleep disordered breathing are particularly exposed to the risk of developing $\mathrm{PH}$. Although $\mathrm{PH}$ in such a context is usually mild, a minority of patients exhibit severe haemodynamic impairment, defined by a mean pulmonary arterial pressure (mPAP) of $\geqslant 35 \mathrm{mmHg}$ or mPAP values ranging between $25 \mathrm{mmHg}$ and $35 \mathrm{mmHg}$ with a low cardiac index $\left(<2 \mathrm{~L} \cdot \mathrm{min}^{-1} \cdot \mathrm{m}^{-2}\right)$. The overlap between lung parenchymal disease and $\mathrm{PH}$ heavily affects life expectancy in such a patient population and complicates their therapeutic management. In this review we illustrate the pathological features and the underlying pathophysiological mechanisms of pulmonary circulation in chronic lung diseases, with an emphasis on COPD, IPF and obstructive sleep apnoea syndrome.

\section{Introduction}

A wide variety of pulmonary diseases with obstructive and/or restrictive lung function impairment may be associated with pulmonary hypertension $(\mathrm{PH})$. In the updated clinical classification of $\mathrm{PH}[1]$, these are placed in group 3, "PH owing to lung diseases and/or hypoxia" (table 1). In this group of diseases, the presence and severity of $\mathrm{PH}$ impact unfavourably on prognosis and thus have a bearing on treatment planning. Also, elucidation of the responsible pathogenetic mechanisms may lead to the development of rational and targeted therapies, which are not yet currently available.

$\mathrm{PH}$ is defined as a mean pulmonary arterial pressure (mPAP) of at least $25 \mathrm{mmHg}$ at rest, as measured by right heart catheterisation [2]. According to the current classification, the consensus definition for $\mathrm{PH}$ in pulmonary parenchymal diseases is determined by an $\mathrm{mPAP}$ value of $\geqslant 25 \mathrm{mmHg}$, while severe $\mathrm{PH}$ is qualified by $\mathrm{mPAP}$ values $\geqslant 35 \mathrm{mmHg}$, or $\mathrm{mPAP} \geqslant 25 \mathrm{mmHg}$ and $\leqslant 35 \mathrm{mmHg}$ but with a low cardiac

Received: Jan 52017 | Accepted after revision: March 12017

Conflict of interest: None declared.

Provenance: Commissioned article, peer reviewed.

Copyright CERS 2017. ERR articles are open access and distributed under the terms of the Creative Commons Attribution Non-Commercial Licence 4.0. 
TABLE 1 Classification of pulmonary hypertension, group 3

1 Pulmonary arterial hypertension

1' Pulmonary veno-occlusive disease and/or pulmonary capillary haemangiomatosis

1" Persistent pulmonary hypertension of the newborn

2 Pulmonary hypertension owing to left heart disease

3 Pulmonary hypertension owing to lung diseases and/or hypoxia

3.1 Chronic obstructive pulmonary disease

3.2 Interstitial lung disease

3.3 Other pulmonary diseases with mixed restrictive and obstructive pattern

3.4 Sleep disordered breathing

3.5 Alveolar hypoventilation disorders

3.6 Chronic exposure to high altitude

3.7 Developmental abnormalities

4 Chronic thromboembolic pulmonary hypertension

5 Pulmonary hypertension with unclear multifactorial mechanisms

Data from [1].

index $\left(<2 \mathrm{~L} \cdot \mathrm{min}^{-1} \cdot \mathrm{m}^{-2}\right)$ [3]. In idiopathic pulmonary fibrosis (IPF), such severe PH carries a very poor prognosis.

Biopsy pathology has no significant role to play in the demonstration of $\mathrm{PH}$ in this group of diseases, or in the assessment of its severity, but it does provide some angle on pathogenesis. Various distinct histological patterns of hypertensive pulmonary vascular disease have been identified in past decades, and these can be linked, to some extent, to different clinical contexts [4]. It is plausible that these various patterns and the differences between them reflect differences in pathogenesis and are, therefore, of potential therapeutic interest. In the rather heterogeneous subgroup of " $\mathrm{PH}$ owing to lung diseases and/or hypoxia", the vascular pathology is heterogeneous as well.

However, our knowledge of histopathology is limited, because it is largely restricted to lung explant and autopsy specimens, except for "pure" hypoxic PH in the absence of pulmonary parenchymal disease, which is easily produced in experimental animals and has its human counterpart in people living at high altitudes, as well as a limited number of conditions of hypoventilation that are unassociated with pulmonary parenchymal disease (see below).

The situation is more complex in lung diseases that, apart from resulting in lung hypoxia, also have associated airway or parenchymal inflammatory or fibrosing disease. The blood vessels of any tissue in the body affected by inflammation and fibrosis display remodelling and the lung is no exception. Such vascular changes are usually a combination of intimal fibrosis with medial and adventitial thickening. Occluding thrombi are not uncommon.

In this review, we discuss the pathology of vascular disease in this heterogeneous group of lung diseases, with special emphasis on possible pathogenetic mechanisms.

\section{"Pure" hypoxic PH: clinical data}

In contrast to the systemic circulation, where tissue hypoxia induces arteriolar vasodilatation, hypoxia of lung tissue results in arterial vasoconstriction [5] and, if the hypoxia persists over long periods of time, induces increased muscle in arterial walls, especially of very small branches. This response is presumably beneficial in the case of unequal ventilation of lung tissue, but it results in $\mathrm{PH}$ when hypoxia globally affects the lungs.

Hypoxic PH is readily produced in animals exposed to decreased air pressure or decreased oxygen concentration in ambient air. In humans, a very similar situation exists in chronic mountain sickness (Monge's disease), a potentially lethal form of hypoxic pulmonary hypertensive disease unassociated with any pulmonary parenchymal disease. Not surprisingly, hypoventilation, such as may result from muscle weakness, thoracic deformities and morbid obesity, results in a similar remodelling of pulmonary arteries and $\mathrm{PH}$. In addition, an increased haematocrit may be associated with increased likelihood of thrombosis, so that thromboembolic events, either clinically manifest or occult, may contribute to the PH. Such post-thrombotic vascular disease is hallmarked histologically by focal lesions, which constitute the remnants of organised and recanalised thrombi; (often eccentric) patches of marked arterial intimal fibrosis, and colander lesions; and organised and recanalised thrombi containing multiple lumina.

Hypoxic pulmonary vasoconstriction is the result of different mechanisms, ranging from a direct effect of hypoxia on smooth muscle vascular cells $[6,7]$, to a decreased release of endothelium-derived vasodilators [8] 
and increased secretion of vasoconstrictors [9, 10]. Rodents exposed to chronic hypoxia develop medial thickening of small pulmonary arteries and muscularisation of arterioles, which normally lack a muscle coat, resulting in reversible $\mathrm{PH}[11,12]$. Similar vascular structural changes have been found in the lungs of healthy high-altitude dwellers [13]. These changes, which are the consequence of hypoxic pulmonary vasoconstriction combined with an increased fluid shear stress, are largely reversible when the hypoxic stimulus is removed [14]. Chronic hypercapnia is also a common finding in patients carrying hypoxic lung disease [15]. Nevertheless, the effect of carbon dioxide on pulmonary vascular tone is controversial, with experimental data providing an effect of both vasoconstriction and vasodilatation $[16,17]$.

Obstructive sleep apnoea syndrome (OSAS) is characterised by recurrent episodes of upper airway obstruction during sleep, resulting in periodic hypoxia, sleep fragmentation and day-time sleepiness. This condition is associated with increased cardiovascular mortality [18, 19]. There is a strong relationship between OSAS and systemic arterial hypertension [20,21] with ischaemic heart disease, atrial fibrillation and stroke [22-27]. Data about the occurrence of $\mathrm{PH}$ in pure, severe OSAS are extremely scant and indicate that severe $\mathrm{PH}$ rarely develops [28]. In addition, some results seem to indicate the reversibility of $\mathrm{PH}$ after treatment of the sleep disorder $[29,30]$.

The mechanisms underlying these associations have only been elucidated incompletely. Excessive sympathetic activity, increased oxidative stress, metabolic alterations and inflammation triggered by intermittent hypoxia are all thought to play a role. Indeed, intermittent hypoxia is known to induce the expression of a variety of inflammatory mediators, including nuclear factor- $\kappa \mathrm{B}(\mathrm{NF}-\kappa \mathrm{B})$ cells, tumour necrosis factor (TNF)- $\alpha$, interleukin (IL)-8 and IL-6 [31-33].

Intermittent hypoxia resulting from sleep apnoea can stimulate the carotid body, the principal chemoreceptor detecting the variations of blood oxygen concentration, resulting in increased sympathetic activity and raised blood pressure during apnoeic episodes [34-36]. Rodents (rats and mice) that have been exposed to intermittent hypoxia manifest an enhanced carotid body chemoreflex response when re-exposed to acute hypoxia $[37,38]$. As is the case with high-altitude $\mathrm{PH}$, hypoxia triggers vasoconstriction of the lung vessels and may induce vascular remodelling characterised by the thickening of the muscular layer of small pulmonary arteries. In addition, left heart dysfunction, which may arise in OSAS, may lead to increased pulmonary venous pressure, which induces muscularisation of pulmonary veins.

The pathogenetic mechanisms of chronic hypoxia-induced vascular changes are still incompletely understood. In pulmonary arterial smooth muscle cells, hypoxia can lead to the shutdown of $\mathrm{K}^{+}$channels, resulting in membrane depolarisation and increased $\mathrm{Ca}^{2+}$ intake. The raised cellular $\mathrm{Ca}^{2+}$ concentration results in sensitisation of the cytoplasmic contractile machinery, leading to arterial vasoconstriction [7]. Hypoxia also generates a stress response in endothelial cells, resulting in the expression of hypoxia inducible factor (HIF)- $1 \alpha$, HIF- $2 \alpha$ and peroxisome proliferator-activated receptor gamma coactivator (PGC)-1 $\alpha$, which are pivotal transcriptional regulators $[39,40]$. The transcription factor HIF-1 is a major regulator of cell oxygen homeostasis that, under hypoxic conditions, shifts cell metabolism towards anaerobiosis [41]. In addition, HIF-1 induces transcription of EPO and VEGF, thus increasing blood oxygen carriage capacity and promoting angiogenesis in hypoxic areas [42, 43]. Known HIF target genes include growth factors such as vascular endothelial growth factor (VEGF) and vascular endothelial growth factor receptor (VEGFR)2, pro-inflammatory cytokines such as stromal cell-derived factor (SDF)1 and chemokine receptor type (CXCR)4, glucose metabolic enzymes such as glucose transporter (Glut)-1 and hexokinase (HK)2, and the activation of pro-survival cellular pathways such as NF- $\mathrm{\kappa B}$ signalling. In hypoxic lung tissue, macrophages release hypoxia-induced mitogenic factor (HIMF), which promotes inflammation and angiogenesis via VEGF and its receptor VEGFR2 [44]. The cytokines released by vascular cells and macrophages may also recruit fibrocytes exhibiting a "inflammatory" phenotype, characterised by the expression of IL-1, IL-6, regulated on activation, normal T-cell expressed and secreted (RANTES), SDF-1 and its receptor CXCR4, osteopontin and the integrin receptor $\alpha v \beta 3$ [45]. The role of IL- 6 as a mediator of $\mathrm{PH}$ in rodents exposed to chronic hypoxia has been well documented [46]. The overexpression of IL-6 in the lungs of mice exposed to chronic hypoxia results in severe $\mathrm{PH}$, characterised by vascular obliterative lesions [47]. Moreover, the increased secretion of IL-6 in hypoxic lungs results in decreased expression of bone morphogenetic protein receptor (BMPR)2, which is mutated in up to $70 \%$ of patients with heritable $\mathrm{PH}[48,49]$. Hypoxic stress also generates endothelial cell production of reactive oxygen species (ROS) and nitrogen species [50], which influence the pulmonary vasomotor state [51]. Thus, chronic hypoxia has an effect on the expression levels of a plethora of vasoconstrictive and inflammatory mediators.

\section{PH in COPD and interstitial lung disease: clinical data}

In chronic obstructive pulmonary disease (COPD), the prevalence of $\mathrm{PH}$ closely parallels the severity of the condition, with up to $90 \%$ of patients having a mPAP of over $20 \mathrm{mmHg}$ at rest. Although $\mathrm{PH}$ is 
usually mild, about $1 \%$ of patients have severe $\mathrm{PH}$, with mPAP values between 35 and $40 \mathrm{mmHg}[52,53]$. The presence and severity of PH in COPD have a substantial impact on survival $[53,54]$.

In idiopathic pulmonary fibrosis (IPF), mPAP values $>25 \mathrm{mmHg}$ are detected in a proportion of patients ranging from $8.1 \%$ to $14.9 \%$ upon initial examination $[55,56]$. In advanced and end-stage disease, these figures have risen to about 50-60\% [57, 58]. Clinical, functional and biological indicators of PH in IPF are worsening dyspnoea, impaired gas exchange at rest and low diffusing capacity of the lung for carbon monoxide.

$\mathrm{PH}$ is a significant prognostic factor in IPF [56], and the prognostic impact of PH in IPF is related to the severity of $\mathrm{PH}$ and pulmonary vascular resistance (PVR) [59] and to a cardiac index below $2.4 \mathrm{~L} \cdot \mathrm{min}^{-1} \cdot \mathrm{m}^{-2}[60]$. Patients with combined emphysema and pulmonary fibrosis are also at high risk to develop $\mathrm{PH}$, which is found in $30-50 \%$ of these patients [61] and may be disproportionally severe. $\mathrm{PH}$ has also been documented as a rare complication occurring in cystic fibrosis [62] and bronchopulmonary dysplasia [63].

The workup for $\mathrm{PH}$ assessment in chronic lung disease first includes non-invasive mPAP assessment by echocardiography. The direct measurement of $\mathrm{PH}$ in chronic lung diseases by right heart catheterisation is required when lung transplantation is considered, or when a disproportional clinical deterioration compared to ventilatory impairment is noted, or in order to validate the diagnosis of $\mathrm{PH}$ in view of patient enrolment in a clinical trial or to confirm left heart dysfunction and to adjust therapy.

\section{Pathogenesis of PH in COPD}

The pathophysiology of COPD is hallmarked by irreversible airflow obstruction. Often, there is some degree of inflammation of the airway walls. The inflammation usually represents a response to protracted exposure to toxic substances, such as those present in tobacco smoke. The inflammatory response is marked by increased numbers of macrophages and T-helper lymphocytes in lung tissue. These are a source of a variety of cytokines and growth factors, such as leukotriene B4, CXC chemokines, IL-1 $\beta$ and IL-6 and profibrogenic transforming growth factor (TGF)- $\beta$. In addition, cigarette smoke and small airway inflammation result in oxidative stress, leading to an increased release of proteases by neutrophils and macrophages and the inactivation of antiproteases, such as $\alpha_{1}$-antitrypsin and secretory leukoprotease inhibitors. The smouldering inflammation leads to airway wall thickening, including an increase in airway wall smooth muscle and hyperplasia of bronchial glands, and is accompanied by increased mucous secretion and ciliary dysfunction of the surface epithelium, all contributing to airflow obstruction. The augmented secretion of bronchial mucus is the result of increased numbers of goblet cells within the surface epithelium and of hyperplasia of submucosal glands. The bronchial inflammation may also induce squamous metaplasia and ciliary dysfunction, impeding the clearance of bronchial secretions. The airflow obstruction following the stagnation of mucous secretions progressively leads to air trapping during expiration, resulting in decreased lung capacity. The main airflow obstruction occurs in airways under $2 \mathrm{~mm}$ in diameter, where pathological changes are designated respiratory bronchiolitis-interstitial lung disease (RB-ILD). The RB is characterised by the accumulation of macrophages within the respiratory bronchiole and adjacent alveoli and by inflammation with mild thickening of the bronchiolar wall and peribronchiolar alveoli [64].

$\mathrm{PH}$ in patients with COPD is the consequence of vasoconstriction as well as structural changes to the vessel walls. The impediments to gas exchange in COPD generate lung tissue hypoxia and hypoxic pulmonary vasoconstriction and remodelling, as outlined in the discussion on high-altitude $\mathrm{PH}$, above. Destruction of the lung parenchyma and the increased airway resistance due to airway wall thickening and bronchial luminal obstruction with mucoid secretions, all contribute to lung hypoxia in COPD [65]. As would be expected, the chronic pulmonary hypoxia in COPD leads to increased medial smooth muscle, especially in small arterial branches [66] (figure 1). In patients with COPD, the hypoxia-induced haemodynamic changes, in conjunction with exposure to toxic agents, engender irreversible vascular structural alterations, characterised by muscularisation of the normally non-muscularised arterioles, as well as medial thickening and neointimal lesions of small and medium-sized pulmonary arteries. Neointimal lesions are characterised by extracellular matrix deposition and proliferation of cells phenotypically similar to smooth muscle cells (SMCs), designated "smooth muscle-like cells" [67, 68]. Smooth muscle-like cells express $\alpha$-smooth muscle actin and vimentin, but not desmin, and probably represent a subset of phenotypically immature SMCs $[69,70]$ (figure 2). They are commonly oriented longitudinally along the vessel lumen, rather than in a circular orientation. Medial hypertrophy of arteries and muscularisation of arterioles are observed in pre-acinar and intra-acinar small pulmonary arterial branches. In severe $\mathrm{PH}$, COPD larger pulmonary arteries also display some degree of medial hypertrophy as well as intimal laminar fibrosis. The occurrence of vascular remodelling in COPD is thought to be related to the synergic action of tobacco smoke and hypoxia. Vascular changes have been documented in non-hypoxaemic COPD 


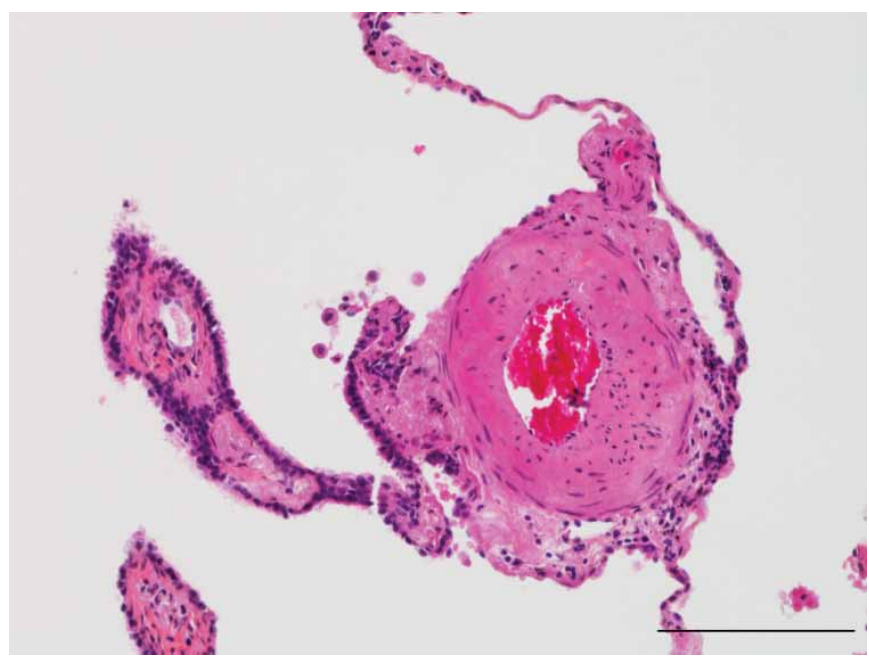

FIGURE 1 Small pulmonary arteries exhibiting irregular intimal and medial thickening within emphysematous lung parenchyma. Haematoxylin-eosin-saffron staining. Scale bar=100 $\mu \mathrm{m}$.

patients, suggesting that the latter can develop independently of hypoxia-induced vasoconstriction. It should be borne in mind, however, that tissue hypoxia may be present focally, in hypoventilated lung areas, so hypoxia-induced haemodynamic changes may occur in the absence of systemic hypoxaemia [71].

In advanced COPD, destruction of the pulmonary vessels is usually mentioned as a contributor to the elevation of mPAP [52]. Nevertheless, studies correlating computed tomography lung tissue density with haemodynamics did not provide any significant association [72, 73]. Nonetheless, it is generally assumed that the capacity of pulmonary vessels for haemodynamic adaptation may be further impaired in the presence of parenchymal destruction, exposing patients to exercise-induced $\mathrm{PH}$ [74].

Hypoxia is not a unique contributor to the development of vascular changes in COPD. Indeed, as indicated above, pulmonary vascular remodelling may also be observed in non-hypoxaemic mild COPD and oxygen therapy is usually insufficient to reverse $\mathrm{PH}$ in COPD patients. The sum of these two observations indicates that other mediators are involved in vascular alterations [75, 76]. Cigarette smoking may result in endothelial dysfunction, with enhanced production and release of growth factors and affluence of
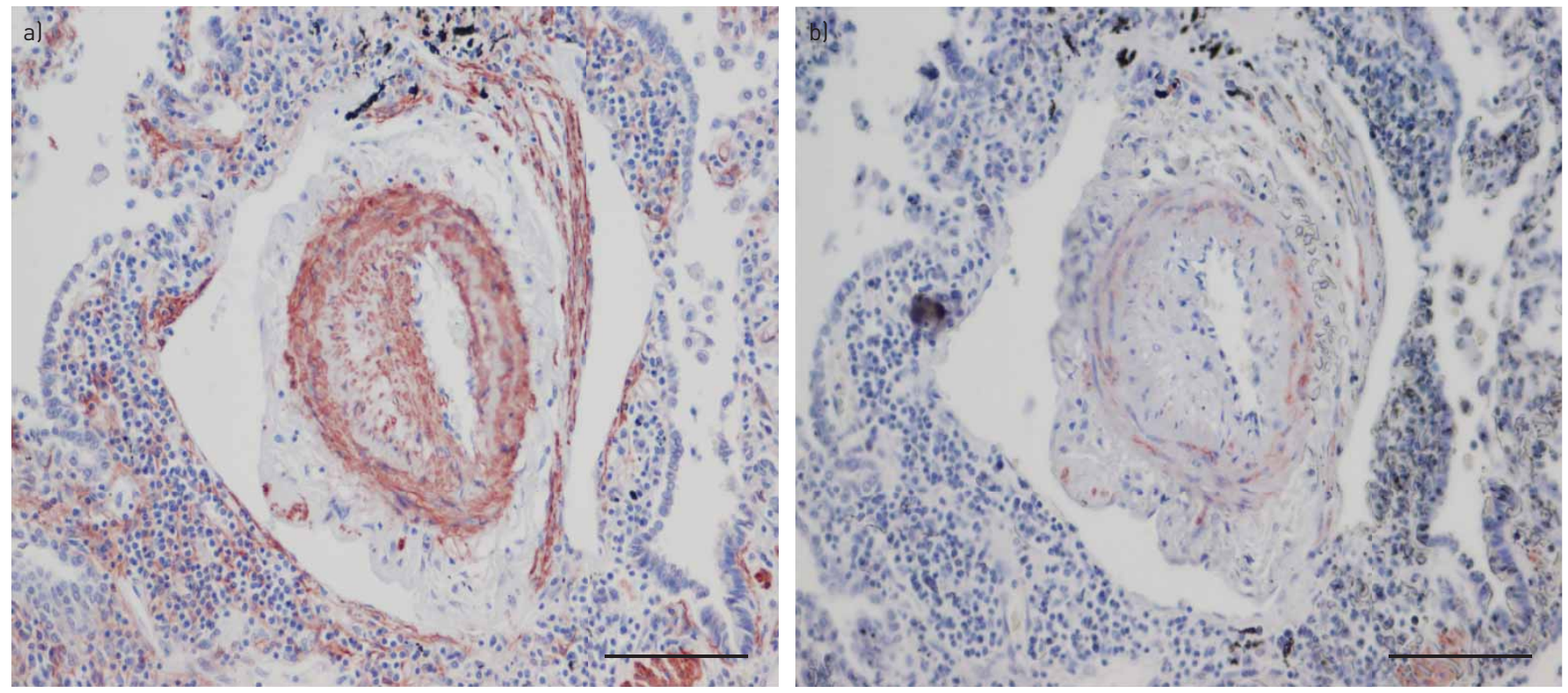

FIGURE 2 a) Actin immunostaining of a remodelled small pulmonary artery. The neointima is thickened by the affluence of cells phenotypically similar to smooth muscle cells (SMC-like cells), expressing actin. b) Desmin immunostaining of the same remodelled pulmonary artery. The neointimal SMC-like cells do not express desmin, unlike medial smooth muscle cells. Both images courtesy of P. Dorfmüller, Hôpital Marie Lannelongue, Le Plessis Robinson, France. Scale bars=100 $\mu \mathrm{m}$. 
inflammatory cells, leading to smooth muscle cells proliferation and vessel wall thickening [77-79]. The biological pathways disrupted by tobacco smoke are largely unexplored, but it is thought that they may be related to oxidative damage [80]. ROS are effective in destroying lung parenchyma by direct damage as well as by inducing inflammation [81]. Nitric oxide (NO) may combine with superoxide $\left(\mathrm{O}^{2-}\right)$ to form the strong oxidant peroxynitrite $\left(\mathrm{ONOO}^{-}\right)[82]$. $\mathrm{ONOO}^{-}$may induce both apoptosis and low proliferation in alveolar epithelial cells [83]. The impact of $\mathrm{ONOO}^{-}$on cell proliferation and survival is achieved via c-Jun N-terminal kinases (JNK) and Src (sarcoma-family kinases) phosphorylation and upregulation of Rtp801 [83]. Moreover, $\mathrm{ONOO}^{-}$can also react with protein tyrosine residues to form the nitrotyrosine, which is considered a marker of cell damage and is increased in COPD lungs $[84,85]$. Tobacco smoke also generates products of lipid peroxidation, such as F2-isoprostanes, 4-hydroxy-2-nonenal, acrolein and malondialdehyde, which trigger cellular redox signalling effects. The oxidative stress can influence primal cell signalling and induce nuclear histone modifications, enhancing the tissue inflammatory response. Investigations of the impact of tobacco smoke on lung circulation in animals have confirmed the hypothesis that tobacco exposure induces muscularisation of pre-capillary vessels and that his happens before the occurrence of emphysema $[86,87]$. Nevertheless, there is no doubt that hypoxia plays a decisive role in COPD vascular changes leading to $\mathrm{PH}$. As airflow obstruction increases, the effects of hypoxaemia on pulmonary circulation may add to the detrimental effects of tobacco smoke.

\section{Pathogenesis of PH in IPF}

IPF is characterised by the progressive scarring of lung tissue, which leads functionally to the deterioration of gas exchange capacity through a restrictive lung function abnormality, in combination with shunting of blood through the vessels running by the fibrotic lung. Usual interstitial pneumonia (UIP) is the histopathological equivalent of IPF. UIP is characterised by a heterogeneous distribution of the fibrosis, predominating in subpleural and basal zones, and results from the accumulation and confluence of fibrosis, which characteristically begins as so-called fibroblast foci, small foci of subepithelial fibroblasts and increased matrix. Scarred areas are juxtaposed next to conserved parenchymal fields, without intervening transition zones. Areas of "active" ongoing fibrosis (represented by fibroblastic foci) coexist with areas of hyaline fibrosis within the scarred regions. Fibroblastic foci are characterised by aggregates of actively proliferating myofibroblasts within a myxoid matrix, oriented with the long axis parallel to the long axis of the alveolar septa. Such aggregates are thought to derive from the organisation of small interstitial exudates. Fibroblastic foci can be readily identified because of their light-staining matrix, rich in proteoglycans, contrasting with the "dark-staining" fibrosis or honeycomb areas. "Honeycomb" changes, which consist of large airspaces surrounded by fibrotic tissue, covered by bronchiolar-type epithelium or hyperplastic type 2 pneumocytes, result from lung architectural restructuring following alveolar injury. A mild inflammatory infiltrate, consisting of small lymphocytes, plasma cells and sometimes neutrophils and eosinophils, is often seen within fibrotic or honeycomb areas. Remodelling of pulmonary vessels is observed both within the fibrotic areas and in unscarred lung parenchyma (figure 3). In the fibrotic zones, small pulmonary arteries display substantial intimal fibrosis and medial hypertrophy. The pulmonary veins are also affected by remodelling,
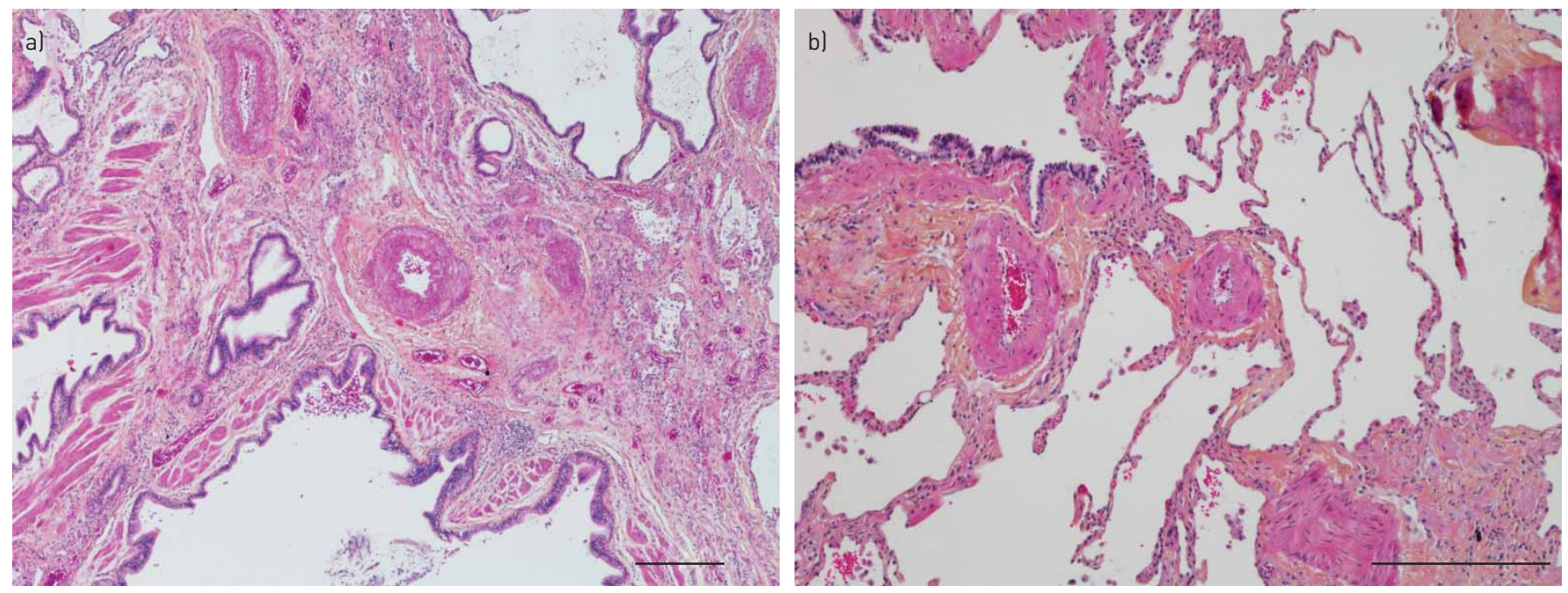

FIGURE 3 al Small pulmonary arteries within a fibrotic area (usual interstitial pneumonia lung). The narrowing of the vascular lumen is the result of both intimal fibrosis and medial smooth muscle increase. Haematoxylin-eosin-saffron staining. Scale bar=250 $\mu$ m. b) Remodelled small pulmonary arteries outside fibrosis in usual interstitial pneumonia lung. Haematoxylin-eosin-saffron staining. Scale bar=200 $\mu \mathrm{m}$. 
exhibiting luminal narrowing by an intimal fibrosis. In architecturally conserved lung zones, some remodelling is seen in pulmonary venules, exhibiting luminal occlusion by acellular fibrous tissue. Such a finding often coexists with alveolar capillary multiplication and muscularisation of pulmonary arterioles [88].

$\mathrm{PH}$ in IPF is increasingly prevalent as IPF progresses. In view of the histological features mentioned above, the occurrence of PH in IPF cannot be explained solely by hypoxic vasoconstriction and the loss of capillary bed through the scarring tissue. To improve the therapeutic management of IPF-associated $\mathrm{PH}$, there is a need to understand the pathobiology of the fibrotic process itself, as well as of the associated vascular remodelling. The density of blood vessels is low in scarred lung regions, while the non-fibrotic tissues at the edge of such regions are richly vascularised. In scarred areas, complex biological processes perturbing the vessels' homeostasis are ongoing. Notably, the imbalance between angiogenetic mediators (such as VEGF) and angiostatic factors (such as pigment epithelium-derived factor (PEDF)) dramatically contributes to pulmonary circulation restructuring, with an increased risk of developing PH. In addition, the effects of oxidative substances and of paracrine molecules released in scarring areas may trigger cellular stress responses and pathobiological processes such as an endothelial to mesenchymal transition, participating in the vascular remodelling.

The pathobiology of vascular remodelling in IPF is complex, and diverse molecules are involved. Such molecules are of potential interest as biomarkers of the progression of the disease and as potential targets of novel therapies.

TGF- $\beta$ is a master regulator of extracellular matrix deposition and fibroblasts proliferation, and it is an acknowledged profibrogenic factor. In the lung, TGF- $\beta$ is produced by macrophages as well as epithelial cells and fibroblasts. It is secreted in the form of an inactive precursor that is activated by proteolytic cleavage. Smad2/3, mitogen-activated protein kinase (MAPK), phosphoinositide 3-kinase (PI3K) and Rho GTPase pathways are activated by interaction of the TGF- $\beta$ receptor with its ligand. Notably, activation of the Smad pathway appears to be crucial for fibroblast proliferation and extracellular matrix (ECM) production culminating in fibrosis [89]. TGF- $\beta$ influences the inflammatory response through the inhibition of immune cell proliferation [90], and is also involved in angiogenesis in a dose-dependent manner [91]. It promotes endothelial cell (EC) apoptosis, differentiation and vascular smooth muscle cell (VSMC) recruitment at high doses, while activating EC at low doses [92]. High TGF- $\beta$ levels in fibrotic areas may indeed contribute to local EC apoptosis, leading to vascular depletion and to an increase in muscularisation of the pulmonary arteries. Indeed, apoptotic ECs in pulmonary fibrotic areas may release growth factors driving VSMC proliferation, such as the platelet-derived growth factor (PDGF) [93-95]. Moreover, the depletion of ECs and endothelial dysfunction in those areas may lead to a decreased production and dropping of vasodilators and inhibitors of VSMC proliferation, such as prostacyclin and NO [95]. In parallel with such phenomena, enhanced release of vasoconstrictors such as endothelin-1, angiotensin and thromboxane $A_{2}$ is documented, contributing to vascular remodelling and to the increase in mPAP $[96,97]$.

VEGF is a chief driver of angiogenesis, with a major role, also, in the homeostasis maintenance of the vascular system. ECs need VEGF signalling for survival and proliferation, and VEGF inhibition leads to capillary alveolar damage, resulting in emphysema. VEGF expression is induced by hypoxia and TGF- $\beta$ stimulation. In lungs, VEGF is mainly secreted by macrophages, epithelial cells, ECs and mesenchymal cells [98]. In IPF, VEGF is markedly reduced within fibrotic areas [99, 100], where its depletion is correlated with EC apoptosis. The level of VEGF is also reduced in the bronchoalveolar lavage fluid of IPF patients.

PDGF is suggested to play a role in fibrosis progression and in pulmonary artery remodelling in IPF, by promoting fibroblast and VSMC proliferation and migration, leading to excessive arterial muscularisation and intimal fibrosis [101]. This finding is also sustained by investigations on experimental models [102]. It is postulated that PDGF acts in an early stage of IPF vascular remodelling, because it can be detected in ECs and VSMCs. PDGF is no longer found in lung vessels in late-stage disease [103]. PDGF could be a relevant target for the inhibition of fibrogenesis and vascular remodelling.

PEDF is found in lung mesenchymal cells, ECs and in bronchial cells. This molecule has a strong angiostatic effect, inhibiting VEGF-induced angiogenesis and inducing EC apoptosis. PEDF can be involved in lung fibrosis, by promoting fibroblast growth, because PEDF is found in the extracellular matrix [104]. Moreover, PEDF inhibition may be an interesting therapeutic target.

Other potential molecular targets limiting fibrosis and vascular remodelling include endostatins, endothelin-1 and angiotensin-II (ATII). In particular, endostatins have an angiostatic effect, through the inhibition of VEGFR2 and matrix metalloproteinase 2 (MMP-2), and are potentially involved in pulmonary artery remodelling in IPF $[105,106]$. Those molecules are generated by the injured lung epithelium from the proteolytic cleavage of collagen XVIII, and their levels in lung tissue seem to be correlated to the degree of lung parenchymal damage in IPF $[107,108]$. Endothelin-1 has vasoconstrictive effects and is also an 
inductor of VSMC growth [97]. Although endothelin seems to be involved in IPF PH, the pharmacological inhibition of its receptor did not result in sufficient clinical improvement [109]. The elevation of ATII within fibrotic areas may therefore contribute to vascular remodelling, providing a solid rationale for research focused on AT inhibition. Moreover, the relevance of ATII as a prognostic biomarker can also be kept in consideration [110].

\section{Conclusion}

Diverse mechanisms are involved in the pathogenesis of pulmonary hypertensive vasculopathy in the setting of parenchymal lung diseases and/or hypoxia. Pulmonary vasoconstriction, triggered by hypoxia, represents the main pathogenetic mechanism in $\mathrm{PH}$ in high-altitude dwellers and in patients with sleep disordered breathing. The persistence of vasoconstriction leads to structural changes in lung vasculature, affecting mostly the small pulmonary arteries. In COPD, hypoxia, the exposure to tobacco smoke and the loss of pulmonary vessels contribute to pulmonary haemodynamic impairment, through vascular remodelling. Finally, PH in UIP is characterised by structural changes involving pulmonary vessels both within the fibrotic areas and outside fibrosis. The biological mechanisms underlying vascular remodelling in UIP are incompletely understood and encompass an altered balance between angiostatic and angioproliferative mediators and the effects of both oxidative and paracrine molecules perturbing vascular cell homeostasis. The occurrence of $\mathrm{PH}$ in parenchymal lung disease complicates the therapeutic attitude and requires the guidance of specialist consultation.

\section{References}

1 Simonneau G, Gatzoulis MA, Adatia I, et al. Updated clinical classification of pulmonary hypertension. J Am Coll Cardiol 2013; 62: Suppl. 7, D34-D41.

2 Hoeper MM, Bogaard HJ, Condliffe R, et al. Definitions and diagnosis of pulmonary hypertension. J Am Coll Cardiol 2013; 62: D42-D50.

3 Seeger W, Adir Y, Barberà JA, et al. Pulmonary hypertension in chronic lung diseases. J Am Coll Cardiol 2013; 62: D109-D116.

4 Grünberg K, Mooi WJ. A practical approach to vascular pathology in pulmonary hypertension. Diagn Histopathol 2013; 19: 298-310.

5 Hales CA. The site and mechanism of oxygen sensing for the pulmonary vessels. Chest 1985; 88: 235S-240S.

6 Archer S, Michelakis E. The mechanism(s) of hypoxic pulmonary vasoconstriction: potassium channels, redox $\mathrm{O}_{2}$ sensors, and controversies. News Physiol Sci 2002; 17: 131-137.

7 Coppock EA, Martens JR, Tamkun MM. Molecular basis of hypoxia-induced pulmonary vasoconstriction: role of voltage-gated $\mathrm{K}^{+}$channels. Am J Physiol Lung Cell Mol Physiol 2001; 281: L1-L12.

8 Aaronson PI, Robertson TP, Ward JPT. Endothelium-derived mediators and hypoxic pulmonary vasoconstriction. Respir Physiol Neurobiol 2002; 132: 107-120.

9 Ward JP, Robertson TP. The role of the endothelium in hypoxic pulmonary vasoconstriction. Exp Physiol 1995; 80: 793-801.

10 Shimoda LA, Sham JSK, Liu Q, et al. Acute and chronic hypoxic pulmonary vasoconstriction: a central role for endothelin-1? Respir Physiol Neurobiol 2002; 132: 93-106.

11 Meyrick B, Reid L. Hypoxia-induced structural changes in the media and adventitia of the rat hilar pulmonary artery and their regression. Am J Pathol; 1980; 100: 151-178.

12 Jeffery TK, Wanstall JC. Pulmonary vascular remodeling: a target for therapeutic intervention in pulmonary hypertension. Pharmacol Ther 2001; 92: 1-20.

13 Heath D, Williams D, Rios-Dalenz J, et al. Small pulmonary arterial vessels of Aymara Indians from the Bolivian Andes. Histopathology 1990; 16: 565-571.

14 Penaloza D, Arias-Stella J. The heart and pulmonary circulation at high altitudes: healthy highlanders and chronic mountain sickness. Circulation 2007; 115: 1132-1146.

15 Xia X-D, Xu Z-J, Hu X-G, et al. Impaired iNOS-sGC-cGMP signalling contributes to chronic hypoxic and hypercapnic pulmonary hypertension in rat. Cell Biochem Funct 2012; 30: 279-285.

16 Brimioulle $\mathrm{S}$, Lejeune $\mathrm{P}$, Vachiery $\mathrm{JL}$, et al. Effects of acidosis and alkalosis on hypoxic pulmonary vasoconstriction in dogs. Am J Physiol 1990; 258: H347-H353.

17 Barer GR, Shaw JW. Pulmonary vasodilator and vasoconstrictor actions of carbon dioxide. J Physiol 1971; 213: 633-645.

18 Marshall NS, Wong KKH, Liu PY, et al. Sleep apnea as an independent risk factor for all-cause mortality: the Busselton Health Study. Sleep 2008; 31: 1079-1085.

19 Young T, Finn L, Peppard PE, et al. Sleep disordered breathing and mortality: eighteen-year follow-up of the Wisconsin sleep cohort. Sleep 2008; 31: 1071-1078.

20 Nieto FJ, Young TB, Lind BK, et al. Association of sleep-disordered breathing, sleep apnea, and hypertension in a large community-based study. Sleep Heart Health Study. JAMA 2000; 283: 1829-1836.

21 Bixler EO, Vgontzas AN, Lin HM, et al. Association of hypertension and sleep-disordered breathing. Arch Intern Med 2000; 160: 2289-2295.

22 Peker Y, Kraiczi H, Hedner J, et al. An independent association between obstructive sleep apnoea and coronary artery disease. Eur Respir J 1999; 14: 179-184.

23 Yaggi HK, Concato J, Kernan WN, et al. Obstructive sleep apnea as a risk factor for stroke and death. $N$ Engl J Med 2005; 353: 2034-2041.

24 Gami AS, Pressman G, Caples SM, et al. Association of atrial fibrillation and obstructive sleep apnea. Circulation 2004; 110: 364-367. 
Zhao FH, Chen YD, Jin $\mathrm{ZN}$, et al. Are impaired endothelial progenitor cells involved in the processes of late in-stent thrombosis and re-endothelialization of drug-eluting stents? Med Hypotheses 2008; 70: 512-514.

Doherty LS, Kiely JL, Swan V, et al. Long-term effects of nasal continuous positive airway pressure therapy on cardiovascular outcomes in sleep apnea syndrome. Chest 2005; 127: 2076-2084.

Marin JM, Carrizo SJ, Vicente E, et al. Long-term cardiovascular outcomes in men with obstructive sleep apnoea-hypopnoea with or without treatment with continuous positive airway pressure: an observational study. Lancet 2005; 365: 1046-1053.

Sajkov D, McEvoy RD. Obstructive sleep apnea and pulmonary hypertension. Prog Cardiovasc Dis 2009; 51: 363-370.

Hawryłkiewicz I, Sliwiński P, Górecka D, et al. Pulmonary haemodynamics in patients with OSAS or an overlap syndrome. Monaldi Arch Chest Dis 2004; 61: 148-152.

Sforza E, Roche F. Chronic intermittent hypoxia and obstructive sleep apnea: an experimental and clinical approach. Hypoxia (Auckl) 2016; 4: 99-108.

Greenberg $\mathrm{H}$, Ye $\mathrm{X}$, Wilson $\mathrm{D}$, et al. Chronic intermittent hypoxia activates nuclear factor-kappaB in cardiovascular tissues in vivo. Biochem Biophys Res Commun 2006; 343: 591-596.

Kletsas D, Pratsinis H, Mariatos G, et al. The proinflammatory phenotype of senescent cells: the p53-mediated ICAM-1 expression. Ann NY Acad Sci 2004; 1019: 330-332.

Tsatsanis C, Androulidaki A, Venihaki M, et al. Signalling networks regulating cyclooxygenase-2. Int J Biochem Cell Biol 2006; 38: 1654-1661.

Wang C, Wang S, Visocchi M, et al. Pre-operative irreducible C1-C2 dislocations: intra-operative reduction and posterior fixation. The "always posterior strategy". Acta Neurochir (Wien) 2009; 151: 551-560.

Ryan S, Ward S, Heneghan C, et al. Predictors of decreased spontaneous baroreflex sensitivity in obstructive sleep apnea syndrome. Chest 2007; 131: 1100-1107.

Prabhakar NR. Sensing hypoxia: physiology, genetics and epigenetics. J Physiol 2013; 591: 2245-2257.

Peng Y-J, Prabhakar NR. Effect of two paradigms of chronic intermittent hypoxia on carotid body sensory activity. J Appl Physiol 2004; 96: 1236-1242.

Peng Y-J, Yuan G, Ramakrishnan D, et al. Heterozygous HIF-1 $\alpha$ deficiency impairs carotid body-mediated systemic responses and reactive oxygen species generation in mice exposed to intermittent hypoxia. $J$ Physiol 2006; 577: 705-716.

Manalo DJ, Rowan A, Lavoie T, et al. Transcriptional regulation of vascular endothelial cell responses to hypoxia by HIF-1. Blood 2005; 105: 659-669.

Rao J, Li J, Liu Y, et al. The key role of PGC- $1 \alpha$ in mitochondrial biogenesis and the proliferation of pulmonary artery vascular smooth muscle cells at an early stage of hypoxic exposure. Mol Cell Biochem 2012; 367: 9-18.

Papandreou I, Cairns RA, Fontana L, et al. HIF-1 mediates adaptation to hypoxia by actively downregulating mitochondrial oxygen consumption. Cell Metab 2006; 3: 187-197.

Fandrey J. Oxygen-dependent and tissue-specific regulation of erythropoietin gene expression. Am J Physiol Regul Integr Comp Physiol 2004; 286: R977-R988.

Cummins EP, Taylor CT. Hypoxia-responsive transcription factors. Pflugers Arch 2005; 450: 363-371.

Yamaji-Kegan K, Su Q, Angelini DJ, et al. Hypoxia-induced mitogenic factor has proangiogenic and proinflammatory effects in the lung via VEGF and VEGF receptor-2. Am J Physiol Lung Cell Mol Physiol 2006; 291: L1159-L1168.

Anwar A, Li M, Frid MG, et al. Osteopontin is an endogenous modulator of the constitutively activated phenotype of pulmonary adventitial fibroblasts in hypoxic pulmonary hypertension. Am J Physiol Lung Cell Mol Physiol 2012; 303: L1-L11.

Savale L, Tu L, Rideau D, et al. Impact of interleukin-6 on hypoxia-induced pulmonary hypertension and lung inflammation in mice. Respir Res 2009; 10: 6.

Steiner MK, Syrkina OL, Kolliputi N, et al. Interleukin-6 overexpression induces pulmonary hypertension. Circ Res 2009; 104: 236-244.

Austin ED, Loyd JE, Phillips JA. Genetics of pulmonary arterial hypertension. Semin Respir Crit Care Med 2009; 30: 386-398.

Brock M, Trenkmann M, Gay RE, et al. Interleukin-6 modulates the expression of the bone morphogenic protein receptor type II through a novel STAT3-microRNA cluster 17/92 pathway. Circ Res 2009; 104: 1184-1191.

Voelkel NF, Bogaard HJ, Husseini Al A, et al. Antioxidants for the treatment of patients with severe angioproliferative pulmonary hypertension? Antioxid Redox Signal 2013; 18: 1810-1817.

Jin N, Packer CS, Rhoades RA. Reactive oxygen-mediated contraction in pulmonary arterial smooth muscle: cellular mechanisms. Can J Physiol Pharmacol 1991; 69: 383-388.

Chaouat A, Bugnet A-S, Kadaoui N, et al. Severe pulmonary hypertension and chronic obstructive pulmonary disease. Am J Respir Crit Care Med 2005; 172: 189-194.

Andersen $\mathrm{KH}$, Iversen $\mathrm{M}$, Kjaergaard J, et al. Prevalence, predictors, and survival in pulmonary hypertension related to end-stage chronic obstructive pulmonary disease. J Heart Lung Transplant 2012; 31: 373-380.

Oswald-Mammosser M, Weitzenblum E, Quoix E, et al. Prognostic factors in COPD patients receiving long-term oxygen therapy. Importance of pulmonary artery pressure. Chest 1995; 107: 1193-1198.

Hamada K, Nagai S, Tanaka S, et al. Significance of pulmonary arterial pressure and diffusion capacity of the lung as prognosticator in patients with idiopathic pulmonary fibrosis. Chest 2007; 131: 650-656.

Kimura M, Taniguchi $\mathrm{H}$, Kondoh $\mathrm{Y}$, et al. Pulmonary hypertension as a prognostic indicator at the initial evaluation in idiopathic pulmonary fibrosis. Respiration 2013; 85: 456-463.

Behr J, Ryu JH. Pulmonary hypertension in interstitial lung disease. Eur Respir J 2008; 31: 1357-1367.

Nathan SD, Shlobin OA, Ahmad S, et al. Serial development of pulmonary hypertension in patients with idiopathic pulmonary fibrosis. Respiration 2008; 76: 288-294.

Corte TJ, Wort SJ, Wells AU. Pulmonary hypertension in idiopathic pulmonary fibrosis: a review. Sarcoidosis Vasc Diffuse Lung Dis 2009; 26: 7-19.

Cottin V, Le Pavec J, Prévot G, et al. Pulmonary hypertension in patients with combined pulmonary fibrosis and emphysema syndrome. Eur Respir J 2010; 35: 105-111.

Cottin V, Nunes $\mathrm{H}$, Brillet P-Y, et al. Combined pulmonary fibrosis and emphysema: a distinct underrecognised entity. Eur Respir J 2005; 26: 586-593. 
62 Manika K, Pitsiou GG, Boutou AK, et al. The impact of pulmonary arterial pressure on exercise capacity in mild-to-moderate cystic fibrosis: a case control study. Pulm Med 2012; 2012: 252345-252346.

63 Berger RMF, Beghetti M, Humpl T, et al. Clinical features of paediatric pulmonary hypertension: a registry study. Lancet 2012; 379: 537-546.

64 Hogg JC, Timens W. The pathology of chronic obstructive pulmonary disease. Annu Rev Pathol 2009; 4: 435-459.

65 Cosio Piqueras MG, Cosio MG. Disease of the airways in chronic obstructive pulmonary disease. Eur Respir J 2001; 18: Suppl. 34, 41s-49s.

66 Stenmark KR, Fagan KA, Frid MG. Hypoxia-induced pulmonary vascular remodeling: cellular and molecular mechanisms. Circ Res 2006; 99: 675-691.

67 Barberà JA, Peinado VI, Santos S. Pulmonary hypertension in chronic obstructive pulmonary disease. Eur Respir J 2003; 21: 892-905.

68 Taraseviciene-Stewart L, Kasahara Y, Alger L, et al. Inhibition of the VEGF receptor 2 combined with chronic hypoxia causes cell death-dependent pulmonary endothelial cell proliferation and severe pulmonary hypertension. FASEB J 2001; 15: 427-438.

69 Santos S, Peinado VI, Ramírez J, et al. Characterization of pulmonary vascular remodelling in smokers and patients with mild COPD. Eur Respir J 2002; 19: 632-638.

70 Owens GK, Kumar MS, Wamhoff BR. Molecular regulation of vascular smooth muscle cell differentiation in development and disease. Physiol Rev 2004; 84: 767-801.

71 Nicolls MR, Mizuno S, Taraseviciene-Stewart L, et al. New models of pulmonary hypertension based on VEGF receptor blockade-induced endothelial cell apoptosis. Pulm Circ 2012; 2: 434-442.

72 Scharf SM, Iqbal M, Keller C, et al. Hemodynamic characterization of patients with severe emphysema. Am J Respir Crit Care Med 2002; 166: 314-322.

73 Biernacki W, Gould GA, Whyte KF, et al. Pulmonary hemodynamics, gas exchange, and the severity of emphysema as assessed by quantitative CT scan in chronic bronchitis and emphysema. Am Rev Respir Dis 1989; 139: $1509-1515$.

74 Wrobel JP, Thompson BR, Williams TJ. Mechanisms of pulmonary hypertension in chronic obstructive pulmonary disease: a pathophysiologic review. J Heart Lung Transplant 2012; 31: 557-564.

75 Timms RM, Khaja FU, Williams GW. Hemodynamic response to oxygen therapy in chronic obstructive pulmonary disease. Ann Intern Med 1985; 102: 29-36.

76 Wright JL, Lawson L, Paré PD, et al. The structure and function of the pulmonary vasculature in mild chronic obstructive pulmonary disease. The effect of oxygen and exercise. Am Rev Respir Dis 1983; 128: 702-707.

77 Peinado VI, Barberà JA, Ramírez J, et al. Endothelial dysfunction in pulmonary arteries of patients with mild COPD. Am J Physiol 1998; 274: L908-L913.

78 Santos S, Peinado VI, Ramirez J, et al. Enhanced expression of vascular endothelial growth factor in pulmonary arteries of smokers and patients with moderate chronic obstructive pulmonary disease. Am J Respir Crit Care Med 2003; 167: 1250-1256.

79 Peinado VI, Barberà JA, Abate $\mathrm{P}$, et al. Inflammatory reaction in pulmonary muscular arteries of patients with mild chronic obstructive pulmonary disease. Am J Respir Crit Care Med 1999; 159: 1605-1611.

80 Rahman I, Adcock IM. Oxidative stress and redox regulation of lung inflammation in COPD. Eur Respir J 2006; 28: 219-242.

81 Wink DA, Feelisch M, Fukuto J, et al. The cytotoxicity of nitroxyl: possible implications for the pathophysiological role of NO. Arch Biochem Biophys 1998; 351: 66-74.

82 Szabó C, Ischiropoulos H, Radi R. Peroxynitrite: biochemistry, pathophysiology and development of therapeutics. Nat Rev Drug Discov 2007; 6: 662-680.

83 Seimetz M, Parajuli N, Pichl A, et al. Inducible NOS inhibition reverses tobacco-smoke-induced emphysema and pulmonary hypertension in mice. Cell 2011; 147: 293-305.

84 Ricciardolo FLM, Sterk PJ, Gaston B, et al. Nitric oxide in health and disease of the respiratory system. Physiol Rev 2004; 84: 731-765.

85 Tzortzaki EG, Tsoumakidou M, Makris D, et al. Laboratory markers for COPD in "susceptible" smokers. Clin Chim Acta 2006; 364: 124-138.

86 Wright JL, Churg A. Short-term exposure to cigarette smoke induces endothelial dysfunction in small intrapulmonary arteries: analysis using guinea pig precision cut lung slices. J Appl Physiol 2008; 104: 1462-1469.

87 Ferrer E, Peinado VI, Díez M, et al. Effects of cigarette smoke on endothelial function of pulmonary arteries in the guinea pig. Respir Res 2009; 10: 76.

88 Colombat $\mathrm{M}, \mathrm{Mal} \mathrm{H}$, Groussard $\mathrm{O}$, et al. Pulmonary vascular lesions in end-stage idiopathic pulmonary fibrosis: histopathologic study on lung explant specimens and correlations with pulmonary hemodynamics. Hum Pathol 2007; 38: 60-65.

89 Gauldie J, Kolb M, Ask K, et al. Smad3 signaling involved in pulmonary fibrosis and emphysema. Proc Am Thorac Soc 2006; 3: 696-702.

90 Prud'homme GJ. Pathobiology of transforming growth factor beta in cancer, fibrosis and immunologic disease, and therapeutic considerations. Lab Invest 2007; 87: 1077-1091.

91 Pertovaara L, Kaipainen A, Mustonen T, et al. Vascular endothelial growth factor is induced in response to transforming growth factor-beta in fibroblastic and epithelial cells. J Biol Chem 1994; 269: 6271-6274.

92 Carmeliet P. Blood vessels and nerves: common signals, pathways and diseases. Nat Rev Genet 2003; 4: 710-720.

93 Khalil N, O'Connor R, Unruh $\mathrm{H}$, et al. Enhanced expression and immunohistochemical distribution of transforming growth factor-beta in idiopathic pulmonary fibrosis. Chest 1991; 99: 65S-66S.

94 Bergeron A, Soler P, Kambouchner M, et al. Cytokine profiles in idiopathic pulmonary fibrosis suggest an important role for TGF-beta and IL-10. Eur Respir J 2003; 22: 69-76.

95 Zaiman AL, Podowski M, Medicherla S, et al. Role of the TGF-beta/Alk5 signaling pathway in monocrotaline-induced pulmonary hypertension. Am J Respir Crit Care Med 2008; 177: 896-905.

96 Perrella MA, Edell ES, Krowka MJ, et al. Endothelium-derived relaxing factor in pulmonary and renal circulations during hypoxia. Am J Physiol 1992; 263: R45-R50.

97 Budhiraja R, Tuder RM, Hassoun PM. Endothelial dysfunction in pulmonary hypertension. Circulation 2004, 109: $159-165$ 
Tuder RM, Yun JH. Vascular endothelial growth factor of the lung: friend or foe. Curr Opin Pharmacol 2008; 8: 255-260.

99 Ebina M, Shimizukawa M, Shibata N, et al. Heterogeneous increase in CD34-positive alveolar capillaries in idiopathic pulmonary fibrosis. Am J Respir Crit Care Med 2004; 169: 1203-1208.

100 Cosgrove GP, Brown KK, Schiemann WP, et al. Pigment epithelium-derived factor in idiopathic pulmonary fibrosis: a role in aberrant angiogenesis. Am J Respir Crit Care Med 2004; 170: 242-251.

101 Antoniades HN, Bravo MA, Avila RE, et al. Platelet-derived growth factor in idiopathic pulmonary fibrosis. J Clin Invest 1990; 86: 1055-1064.

102 Schermuly RT, Dony E, Ghofrani HA, et al. Reversal of experimental pulmonary hypertension by PDGF inhibition. J Clin Invest 2005; 115: 2811-2821.

103 Homma S, Nagaoka I, Abe H, et al. Localization of platelet-derived growth factor and insulin-like growth factor I in the fibrotic lung. Am J Respir Crit Care Med 1995; 152: 2084-2089.

104 Bensadoun ES, Burke AK, Hogg JC, et al. Proteoglycan deposition in pulmonary fibrosis. Am J Respir Crit Care Med 1996; 154: 1819-1828.

105 Clamp AR, Jayson GC. The clinical potential of antiangiogenic fragments of extracellular matrix proteins. $\mathrm{Br} \mathrm{J}$ Cancer 2005; 93: 967-972.

106 Paddenberg R, Faulhammer P, Goldenberg A, et al. Hypoxia-induced increase of endostatin in murine aorta and lung. Histochem Cell Biol 2006; 125: 497-508.

107 Yang IV, Burch LH, Steele MP, et al. Gene expression profiling of familial and sporadic interstitial pneumonia. Am J Respir Crit Care Med 2007; 175: 45-54.

108 Thickett DR, Poole AR, Millar AB. The balance between collagen synthesis and degradation in diffuse lung disease. Sarcoidosis Vasc Diffuse Lung Dis 2001; 18: 27-33.

109 Jeffery TK, Morrell NW. Molecular and cellular basis of pulmonary vascular remodeling in pulmonary hypertension. Prog Cardiovasc Dis 2002; 45: 173-202.

110 Specks U, Martin WJ, Rohrbach MS. Bronchoalveolar lavage fluid angiotensin-converting enzyme in interstitial lung diseases. Am Rev Respir Dis 1990; 141: 117-123. 